\title{
NITROGEN CONTENT OF SOME STANDARD-SAMPLE STEELS
}

\author{
By J. G. Thompson and E. H. Hamilton
}

\section{ABSTRACT}

The nitrogen contents of four Standard Samples of iron and steel have been determined by both the vacuum fusion and solution-distillation (Allen) methods. These four standard samples, with nitrogen contents ranging from 0.005 to 0.028 per cent, are now available as nitrogen standards for analysts interested in this determination.

Repeated analyses of several standard samples of iron and steel showed that the nitrogen content of these samples did not change over periods as long as 13 years.

\section{CONTENTS}

Page

I. Introduction

II. The use of standard samples of iron and steel as nitrogen standards.- $\quad 593$

III. The nitrogen content of four current standard samples.... 594

\section{INTRODUCTION}

Studies of various methods for the determination of nitrogen in ferrous materials have been made at the Bureau of Standards for a number of years. Two methods have been commonly used, the vacuum-fusion method and the solution-distillation method, the latter usually referred to as the Allen method. Both methods have been described in detail in previous publications from the Bureau of Standards ${ }^{1} \&$ and in the recent book by Lundell, Hoffman, and Bright. $^{3}$ These and other methods for the determination of nitrogen in steel were summarized in a recent publication ${ }^{4}$ by one of the present authors.

\section{THE USE OF STANDARD SAMPLES OF IRON AND STEEL AS NITROGEN STANDARDS}

During the investigation of methods for the determination of nitrogen, Bureau of Standards standard samples Nos. 8b, 23, and 55 have been in intermittent use as reference standards over periods of from 9 to 13 years. Samples $8 \mathrm{~b}$ and 23 are Bessemer steels containing 0.1 and 0.8 per cent carbon, respectively; sample 55 is an ingot iron. The uniform and reproducible results recorded in Table 1, show that these three standard samples constitute satisfactory reference standards for the determination of nitrogen. A question might be raised as to the stability or permanence of the nitrides present in irons and steels but it is evident, from the data in Table 1, that the nitrogen content of these samples did not change with time during approximately 10 years.

1 L. Jordan and F. E. Swindells, Gases in Metals. I. The Determination of Combined Nitrogen in Iron and Steel and the Change in Form of Nitrogen by Heat Treatment, B. S. Sci. Paper No. 457, 1922.

2 H. C. Vacher and L. Jordan, The Determination of Oxygen and Nitrogen in Irons and Steels by the Vacuum Fusion Method, B. S. Jour. Research, vol. 7 (RP346), August, 1931

3 G. E. F. Lundell, J. I. Hoftman, and H. A. Bright, Chemical Analysis of Iron and Steel, John Wiley \& Sons (Inc.), 1931

J. G. Thompson, Determination of Oxygen, Nitrogen, and Hydrogen in Steel, Am. Inst. Min. \& Met. Eng., Tech. Pub. No. 466, 1932. 


\section{THE NITROGEN CONTENT OF FOUR CURRENT STANDARD SAMPLES}

The available supply of two of these three samples has been exhausted. In order that nitrogen standards may be readily available to workers interested in this determination, the nitrogen content of some of the current standard samples was determined. Four standard samples, No. 10d (Bessemer steel, 0.4 per cent C); No. 55 (ingot iron); No. 101 ("18-8" chromium-nickel stainless steel); and No. 106 (nitriding steel) were chosen, representing different types of iron and steel with different nitrogen contents. Nos. $10 \mathrm{~d}$ and 55 represent the older, simpler types of ferrous materials with low or medium nitrogen content. Nos. 101 and 106 represent newer types of steel, with medium or high nitrogen content, in which more importance may be attached to the presence of nitrogen. Determinations of nitrogen by both the Allen method and the vacuum-fusion method show that sample No. $10 \mathrm{~d}$ contains 0.008 per cent; No. $55,0.005$ per cent; No. $101,0.028$ per cent; and No. 106, 0.009 per cent, as recorded in Table 2.

TABLE 1.-Permanence of the nitrogen content of Bureau of Standards standard samples

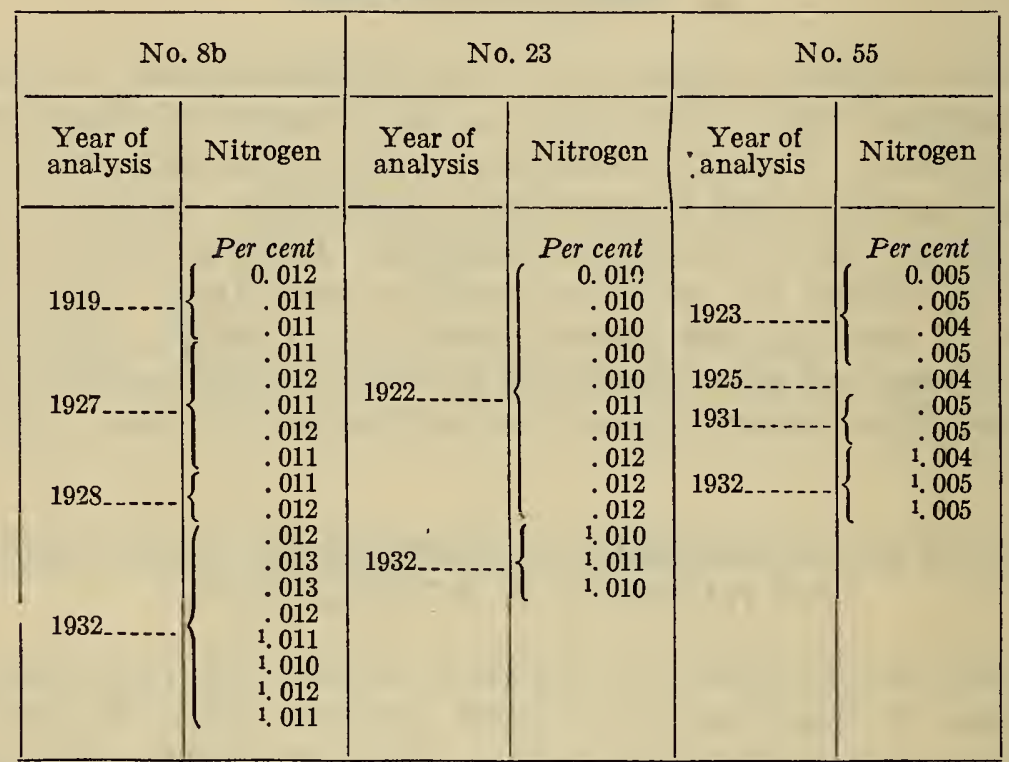

\footnotetext{
1 Determinations made by the vacuum-fusion method. All other determinations were made by the Allen method.

Attention is called to the fact that certain precautions must be observed in order to obtain satisfactory results in the analysis of the nitriding steel, No. 106, by the vacuum-fusion method. The nitrides in this steel are decomposed more slowly in the vacuum-fusion method than are the nitrides of plain carbon steels, and it is necessary to continue the extraction of gases from the sample somewhat longer than usual, in order to insure complete recovery of nitrogen. If this precaution is observed complete recovery of nitrogen is secured, as is indicated by the agreement between the results from the two methods of analysis recorded in Table 2.
} 
TABLE 2.-Nitrogen content of current standard samples

\begin{tabular}{|c|c|c|c|c|c|c|c|}
\hline No. 10d nitrogen & $\begin{array}{c}\text { No. } 55 \\
\text { nitrogen }\end{array}$ & $\begin{array}{l}\text { No. } 101 \\
\text { nitrogen }\end{array}$ & $\begin{array}{l}\text { No. } 106 \\
\text { nitrogen }\end{array}$ & No. 10d nitrogen & $\begin{array}{c}\text { No. } 55 \\
\text { nitrogen }\end{array}$ & $\begin{array}{l}\text { No. } 101 \\
\text { nitrogen }\end{array}$ & $\begin{array}{l}\text { No. } 106 \\
\text { nitrogen }\end{array}$ \\
\hline $\begin{array}{l}\text { Per cent } \\
10.008 \\
1.008 \\
1.009 \\
1.009\end{array}$ & $\begin{array}{c}\text { Per cent } \\
10.004 \\
1.005 \\
1.005 \\
1.005\end{array}$ & $\begin{array}{c}\text { Per cent } \\
10.028 \\
1.028 \\
1.028 \\
1.028\end{array}$ & $\begin{array}{l}\text { Per cent } \\
10.009 \\
1.011 \\
1.010 \\
1.008\end{array}$ & $\begin{array}{r}\text { Per cent } \\
0.008 \\
.009 \\
.008 \\
.008\end{array}$ & $\begin{array}{c}\text { Per cent } \\
0.005 \\
.005 \\
.005\end{array}$ & $\begin{array}{c}\text { Per cent } \\
0.028 \\
.028 \\
.028 \\
.027\end{array}$ & $\begin{array}{c}\text { Per cent } \\
10.009 \\
1.009 \\
.010 \\
.010\end{array}$ \\
\hline $\begin{array}{r}1.009 \\
1.008 \\
.008 \\
.008\end{array}$ & $\begin{array}{l}.005 \\
.004 \\
.005 \\
.004\end{array}$ & $\begin{array}{r}1.028 \\
.026 \\
.028 \\
.027\end{array}$ & $\begin{array}{l}1.010 \\
1.008 \\
1.007 \\
1.009\end{array}$ & Average .008 & .005 & .028 & $\begin{array}{l}.009 \\
.009 \\
.010 \\
.010 \\
.009\end{array}$ \\
\hline
\end{tabular}

1 Determinations made by the vacuum-fusion method. Remaining determinations made by the Allen method.

In view of the numerous requests, which have been received for material to be used as reference standards in the determination of both oxygen and nitrogen, it is unfortunate that these standard samples can not be used as reference standards for oxygen as well as for nitrogen in the vacuum-fusion method. The standard samples are prepared in the form of small, uniform millings, and experience has shown that such samples yield values much too high in the determination of oxygen by the vacuum-fusion method. During the milling process the surface of each chip becomes coated with a thin film of oxide, especially if the chips become heated. In addition to this oxide film, water is usually present as a result of condensation or adsorption during handling and storage. The actual amount of oxygen in the oxide or moisture film on any one chip is very small, but the total from a large number of chips may equal or even exceed the amount of oxygen present in the solid metal of the sample. It is impossible to distinguish between "surface oxygen" and "dissolved oxygen" in the vacuum-fusion method. Consequently, solid specimens with small surface area and correspondingly small contents of "surface oxygen" are preferred for the vacuum-fusion determination of oxygen. The presence of these surface films does not, however, interfere with the determination of nitrogen, and these standard samples are therefore available as nitrogen standards.

Washington, July 18, 1932. 